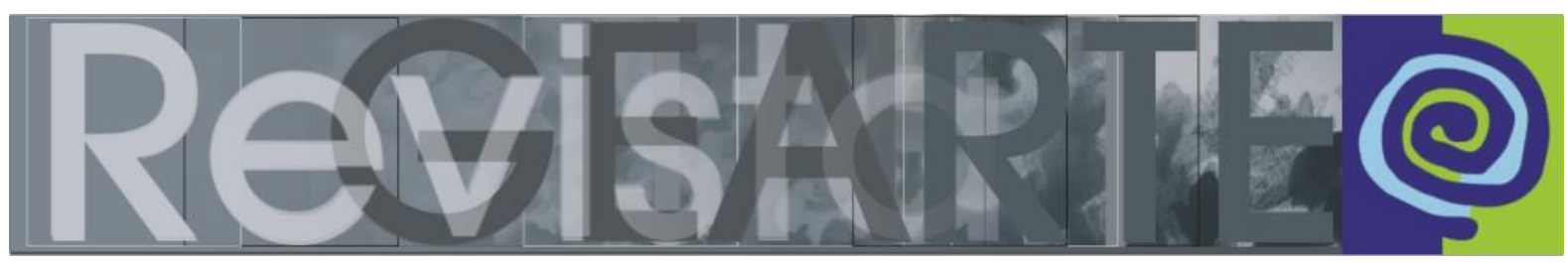

e-ISSN 2357-9854

\title{
Diálogos entre Educação e Arte: GEARTE 21 anos
}

Analice Dutra Pillar

(Universidade Federal do Rio Grande do Sul — UFRGS, Porto Alegre/RS, Brasil)

Maria Helena Wagner Rossi

(Universidade de Caxias do Sul — UCS, Caxias do Sul/RS, Brasil)

Vinte e um anos! Um grupo de pesquisa completar mais de duas décadas de trabalho é uma conquista. Em 2018 celebramos os 21 anos do Grupo de Pesquisa em Educação e Arte (GEARTE), que nasceu em 1997 do desejo de professores e orientandos vinculados à linha de pesquisa Educação e Arte, do Programa de PósGraduação em Educação (PPGEDU) da Faculdade de Educação (FACED) da Universidade Federal do Rio Grande do Sul (UFRGS). Nosso interesse era criar um coletivo de modo a compartilhar as pesquisas de mestrado e de doutorado que estavam sendo feitas na área de educação e arte.

A ideia de constituir um grupo de pesquisa começou a ser esboçada nos seminários com os orientandos das professoras Esther Beyer e Analice Pillar no PPGEDU. Tal projeto recebeu grande acolhida do coordenador do Programa, professor Dr. Nilton Bueno Fischer, e foi compartilhada com professores da Faculdade de Educação - Gabriel de Andrade Junqueira Filho, Sergio Lulkin, Susana Vieira da Cunha, Tania Marques e Leda Maffioletti —, do Instituto de Artes da UFRGS Umbelina Barreto, Vera Bertoni, Mirna Spritzer e Gisela Habeyche - e de outras instituições - Gilberto Icle e Maria Isabel Petry Kehrwald (FUNDARTE), Maria Helena Wagner Rossi, Gládis Franck da Cunha, Neiva Panozzo, Mara Galvani e Carmen Capra (UCS), Sandra Richter (UNISC), Marly Meira (URCAMP), Ângela Pohlmann (UFPEL), Marlene François (UNIJUÍ), Celso Vitelli e Bento de Abreu (ULBRA), Ana Marta Meira, Ana Laura Rolim da Frota, Dulcimarta Lemos Lino, Cláudia Bellochio e Luís Fernando Lazzarin (UFSM). Os professores, advindos das áreas de artes visuais, teatro e música, com garra e entusiasmo criaram o Grupo.

PILLAR, Analice Dutra; ROSSI, Maria Helena Wagner. Diálogos entre educação e arte: GEARTE 21 anos. 
O GEARTE foi um dos primeiros grupos em educação e arte cadastrados no Diretório de Pesquisa do Conselho Nacional de Desenvolvimento Científico e Tecnológico (CNPq/Brasil). É um grupo que começou num jantar entre amigos, no dia 20 de junho de 1997, e hoje envolve professores de diferentes estados do Brasil (Paraná, Pernambuco, Rio Grande do Norte, Rio Grande do Sul, Santa Catarina e São Paulo) e de Moçambique.

Consideramos importante, ao festejar os 21 anos do GEARTE, dar visibilidade aos trabalhos do Grupo neste momento em que a pesquisa no Brasil está passando por uma crise, com cortes de financiamentos de bolsas e projetos. Isso vai significar um grande retrocesso, porque a pesquisa não está só nos laboratórios ou nos ateliers; ela está no nosso cotidiano, nos tecidos que vestimos, nos alimentos, na tecnologia envolvida na produção de imagens, no que escutamos, no ar que respiramos, no design dos objetos, nos equipamentos, nas nossas aulas. Pesquisa e ensino se entrelaçam na nossa práxis docente.

Ao constituirmos o Grupo, importava evidenciar a arte como um campo de conhecimento, mostrar as especificidades da construção de conhecimento em arte e sua relevância na educação. A arte na escola não era uma disciplina no currículo, era considerada como uma atividade artística (LDB 5692/71). Depois de muita mobilização dos professores de artes através das Associações de Arte/Educadores e de longas disputas, em 1996, na Lei de Diretrizes e Bases da Educação Brasileira LDB 9394/96 —, a Arte tornou-se um componente curricular obrigatório na Educação Básica.

Foi uma conquista, mas era preciso qualificar o ensino da arte através da formação docente e de aportes teórico-metodológicos consistentes. Nessa perspectiva, os trabalhos e as pesquisas de Ana Mae Barbosa, em especial a Abordagem Triangular, foram fundamentais para repensarmos o ensino da arte como produção, leitura e contextualização. Em sintonia com tais inquietações, as pesquisas que estávamos realizando no GEARTE tinham por foco destacar os processos de construção de conhecimento nas linguagens artísticas, tanto das artes visuais, como 
do teatro e da música; a compreensão estética; a formação de professores; e as interações em espaços educativos.

No final da década de 1990, viemos a conhecer duas teorias que propiciaram um giro conceitual em nossas pesquisas sobre leitura de imagens: a semiótica discursiva e a cultura visual. O primeiro contato com a teoria semiótica discursiva foi através dos estudos da professora Ana Claudia de Oliveira, que coordena juntamente com o professor Eric Landowski, diretor do Centro de Pesquisa em Ciências Políticas de Paris (CNRS- FNSP-CEVIPOF), o Centro de Pesquisas Sociossemióticas da Pontifícia Universidade Católica de São Paulo (PUCSP). A semiótica discursiva desenvolvida por Algirdas Julien Greimas proporcionou aportes teóricos e metodológicos para a análise da produção de efeitos de sentido em nossas interações com produções imagéticas da arte, da mídia e do cotidiano. O foco de nossos trabalhos se voltou para a análise do percurso gerativo de sentido e dos regimes de interação nos encontros com textos visuais, audiovisuais e sincréticos.

Ana Claudia de Oliveira esteve conosco ministrando conferências, assessorando pesquisas e participando como examinadora de dissertações e teses. Em 2010, o Grupo promoveu a conferência Regimes de interação e sentido na educação com Eric Landowski e também uma reunião de assessoria às pesquisas. Ao nos aproximarmos dos estudos semióticos, realizamos eventos com importantes semioticistas. Lucia Teixeira, da Universidade Federal Fluminense (UFF), ministrou a conferência Autorretratos de lberê Camargo e participou como examinadora de trabalhos de mestrado. Maria da Graça Krieger (UFRGS) fez a conferência Semiótica discursiva: fundamentos para a lexicografia e a terminologia. O Grupo realizou o encontro vasas.cidades. Dos Alpes ao Ilha de Capri com Lucimar Frange, da Universidade Federal de Uberlândia (UFU), que apresentou seus estudos de pósdoutorado em semiótica e analisou trabalhos de mestrado e de doutorado. Sandra Ramalho e Oliveira, da Universidade do Estado de Santa Catarina (UDESC), fez a conferência Imagem também se lê e examinou teses. Moema Rebouças, da Universidade Federal do Espírito Santo (UFES), foi examinadora de trabalhos de doutorado.

PILLAR, Analice Dutra; ROSSI, Maria Helena Wagner. Diálogos entre educação e arte: GEARTE 21 anos. 
O encontro com os estudos da cultura visual foi através do professor Fernando Hernández, da Universitat de Barcelona (UB, Espanha). Em 2003, em um evento em Porto Alegre, apresentamos nossas pesquisas a Hernández e assinamos um acordo entre a UFRGS e a UB para intercâmbio e desenvolvimento de pesquisas, cursos e publicações. Através desse acordo, alguns participantes do GEARTE estudaram na Universidad de Barcelona e Fernando Hernández tem compartilhado a orientação de alunos em estágio de doutorado sanduíche, que trabalham na linha da cultura visual. Além disso, Hernández esteve em Porto Alegre, em diferentes momentos, realizando conferências, cursos e assessorando a pesquisas.

Em 2012, através de um estágio de pós-doutorado houve uma aproximação com os estudos da professora María Acaso, da Universidad Complutense de Madrid (UCM, Espanha), e com seu grupo de pesquisa Pedagogías Invisibles, que vem trabalhando com a cultura visual e com a teoria semiótica em suas investigações. No ano seguinte, o GEARTE organizou, em parceria com a Fundação Bienal do Mercosul, a vinda de María Acaso a Porto Alegre para uma conferência na Bienal, assessoria às pesquisas do GEARTE e realização do curso rEDUvolution: o Ensino da Arte como Processo de Criação Contemporânea, que congregou professores de diferentes áreas do conhecimento, redes e níveis de ensino, pesquisadores, artistas e mediadores. Posteriormente a professora María Acaso foi coorientadora de duas alunas em estágio de doutorado sanduíche na UCM.

Como uma forma de divulgar nossas pesquisas, organizamos os livros Ideias em educação musical, A educação do olhar no ensino das artes e Cor, som e movimento, publicados pela editora Mediação, os quais têm sido referência para outros trabalhos na área do ensino da arte. E para que nossas pesquisas retornassem às escolas, reverberando nas práticas docentes e na formação de professores, criamos com a Editora Mediação a coleção Educação e Arte. O primeiro número da coleção foi Brincadeira e conhecimento, a dissertação de Vera Bertoni dos Santos, que analisa o processo de criação teatral com crianças de educação infantil. Depois, 
foram publicados os livros Imagens que falam ${ }^{1}$, a tese de Maria Helena Rossi, que se centra no processo de compreensão estética dos estudantes do ensino fundamental; A formação do ator, dissertação de Mirna Spritzer, que aborda o processo de criação do aluno ator; Filosofia da criação, tese de Marly Meira, que oferece uma reflexão sobre o significado do sensível em práticas estéticas contemporâneas; e Criança e pintura, dissertação de Sandra Richter, que traz um estudo sobre o processo de criação na linguagem da pintura com crianças de educação infantil.

Organizamos, também, um dossiê sobre educação e arte para a revista Educação \& Realidade, em 2005, no qual procuramos mostrar a diversidade de teorias que embasam nossas pesquisas e de que forma elas dialogam com estudos de pesquisadores nacionais e estrangeiros. E desde 2014 o Grupo publica a Revista GEARTE, que está em seu sexto ano, com três números a cada ano.

Outra forma de diálogo com pesquisadores e docentes para difundir nossos trabalhos é através dos eventos. Muitos foram realizados muitos nesses 21 anos do GEARTE; destacaremos, aqui, somente alguns. Em 2003, promovemos a I Jornada do GEARTE: educação e arte uma dança que se faz coletiva, com a participação de professores de artes de diversas cidades do estado do Rio Grande do Sul. Em julho de 2004, o Grupo organizou o curso Educação e os muitos sentidos do sensível, como parte do XVIII Festival de Arte da cidade de Porto Alegre. Foram cinco oficinas, cada uma para um dos cinco sentidos, e conferências com a participação de João Francisco Duarte Jr., da Universidade de Campinas (UNICAMP); Malvina Dorneles, da UFRGS; João Jardim, diretor do filme Janela da Alma, e Neka Menna Barreto, chef.

Promovemos palestras e conferências sobre educação e arte com a participação de professores de diversas universidades do país, entre os quais destacamos: Ana Mae Barbosa (USP, Anhembi Morumbi), Sebastião Pedrosa

1 Este livro está na 5a edição e foi selecionado pelo Programa Nacional Biblioteca da Escola (PNBE, 2011), do Ministério da Educação, para fazer parte da biblioteca de mais de 41 mil escolas públicas brasileiras das redes federal, estadual e municipal. 
(UFPE), Lucimar Frange (UFU), Fernando de Azevedo (UFPE), Mirian Celeste Martins (Universidade Mackenzie) e Marlene François (UNIJUI).

Em 2009, em parceria com a equipe do Santander Cultural de Porto Alegre, coordenado por Liliana Magalhães, organizamos o encontro Ensino da arte $e$ interterritorialidade, com a participação de Ana Mae Barbosa (USP, Anhembi Morumbi); Ivone Richter (UFSM) e Lilian Amaral (UNESP), que reuniu mais de 300 pessoas. Em 2011 foi organizado o encontro Ensino da Arte, Abordagem Triangular e Culturas Visuais, com Ana Mae Barbosa, Fernando de Azevedo, Rosana Medeiros (Departamento de Educação da cidade de Canoas-RS); Maria Helena Rossi (UCS); Ruth Lerm e Donald Kerr Jr. (IFSul-Pelotas). Nesse mesmo ano, o Grupo participou como um dos polos de transmissão simultânea do evento internacional Em nome das artes ou em nome dos públicos?, que ocorreu em Lisboa, Portugal, promovido pela Culturgest. Em 2012, no seminário 40 anos do PPGEDU, o Grupo apresentou um panorama de suas pesquisas em educação e artes visuais.

Em 2013, em parceria com a Bienal de Artes Visuais do Mercosul, realizamos um curso e uma conferência com a professora María Acaso (UCM, Espanha). No ano seguinte, realizamos um encontro com o professor João Paulo Queiroz, da Universidade de Lisboa, no qual apresentamos nossas investigações e publicações. Em 2015, organizamos o lançamento do livro "Redesenhando o desenho" com conferência da professora Ana Mae Barbosa. E no ano seguinte, promovemos um evento em homenagem aos 80 anos de Ana Mae, com a participação de professores, artistas e alunos de diferentes cidades e estados brasileiros. Em 2017, realizamos a conferência "Desenho infantil em contextos multiculturais" com a professora Pilar Pérez, da Universidad Autónoma de Madrid (UAM, Espanha).

E em 2018, organizamos o evento "Diálogos entre Educação e Arte: GEARTE 21 anos", com a Mesa "Trajetórias de Pesquisa" com Sandra Richter (UNISC), Maria Isabel Petry Kehrwald (FUNDARTE), Ruth Lerm (IFSUL- Pelotas), Rosana Medeiros (SME-Canoas), Maria Helena Rossi (UCS) e Analice Pillar (UFRGS) e a Mesa "Pesquisas em Arte/Educação: provocações", com a participação do professor 
Fernando de Azevedo (UFPE), da professora Fernanda Cunha (UFG) e da professora Maria Helena Rossi (UCS).

O GEARTE é, então, um grupo interinstitucional que, em suas dissertações e teses, pesquisa as relações entre educação e arte, em diálogo com as áreas da semiótica discursiva, cultura visual, estética, história, teoria e crítica da arte. Está formado por professores e estudantes de pós-graduação da UFRGS, Universidade Pedagógica de Moçambique (UP), Universidade Federal de Pernambuco (UFPE), Universidade Federal do Rio Grande do Norte (UFRN), Universidade de Caxias do Sul (UCS), Universidade Católica de Pelotas (UCPEL), Instituto Federal de Educação, Ciência e Tecnologia Sul-Rio-Grandense, campus Pelotas (IFSul-Pelotas), Instituto Federal de Educação, Ciência e Tecnologia de Santa Catarina (IFSC).

O Grupo tem cinco linhas de atuação: pesquisa, docência, estudos específicos, assessoria e publicação. As pesquisas têm tematizado os vínculos entre educação e arte com o objetivo de contribuir para a expansão das perspectivas educativas da arte em diferentes contextos. Para promover nossas pesquisas, participamos em congressos nacionais e internacionais, publicamos artigos em revistas especializadas e organizamos livros. A Revista GEARTE surgiu de nosso interesse em reunir estudos e pesquisas realizados nessa área no país, em diálogo com trabalhos desenvolvidos em outros países.

As atividades de ensino e assessoria incluem seminários avançados na pósgraduação, cursos, palestras, encontros e conferências a cargo de especialistas do Brasil e de outros países. Ainda, em relação à docência, os participantes do GEARTE frequentemente colaboram com instituições diversas daquelas com as quais possuem vínculo permanente, gerando intercâmbio tanto com outras Universidades, quanto com diferentes instituições. Temos, também, participantes que têm atuado junto à Fundação Bienal de Artes Visuais do Mercosul na formação presencial e a distância de mediadores, bem como na coordenação pedagógica e supervisão desses profissionais durante diversas edições desta mostra. 
Em nossas pesquisas, fizemos interlocuções com pesquisadores e teóricos de diversos países. Ana Mae Barbosa tem estado conosco em vários momentos, desde a criação do Grupo, em conferências, assessoria às pesquisas e participando como examinadora de dissertações e teses. Ana Claudia de Oliveira e Eric Landowski ministraram conferências e deram assessoria a nossas pesquisas. Fernando Hernández compartilhou a orientação de alunos em doutorado sanduíche na Espanha. María Acaso esteve conosco em assessoria às pesquisas, curso e conferência. Realizamos, também, eventos com conferências de professores brasileiros e estrangeiros, lançamentos de livros, oficinas. Teóricos como Michael Parsons (University of Illinois) e Jorge Larrosa (Universitat de Barcelona) participaram, de modo virtual ou presencial, de atividades junto ao grupo.

Nesses 21 anos, muitas pessoas colaboraram com o GEARTE, pesquisadores e estudantes. No PPGEDU diversos colegas foram parceiros em várias ações. Gostaria de referir, em especial, os professores Dra. Esther Beyer, Dra. Regina Mutti, Dr. Fernando Becker, Dr. Nilton Fischer, Dr. Gabriel Junqueira, Dra. Margarete Axt, Dra. Malvina Dornelles, Dra. Rosa Fischer, Dra. Maria Stephanou e Dra. Luciana Loponte. Nas atividades conjuntas realizadas com o Instituto de Artes da UFRGS tivemos a parceria das professoras Dra. Icléia Cattani e Dra. Mônica Zielinsky.

Nos primeiros anos, os professores e artistas que participaram do Grupo eram de diversas áreas: artes visuais, teatro, música, psicologia e educação infantil. Alguns participantes posteriormente formaram seus próprios grupos de pesquisa em áreas específicas, o que é, de certa forma, uma contribuição do GEARTE na constituição desses outros grupos. Recentemente, o GEARTE apoiou a constituição do Grupo de Estudos em Educação e Arte (GE Educação e Arte da ANPED), que em 2008 se consolidou como um Grupo de Trabalho.

Com 28 pesquisadores brasileiros e estrangeiros de diversas instituições, 0 GEARTE tem como líder Analice Dutra Pillar (UFRGS) e como vice-líder Maria Helena Wagner Rossi (UCS), numa trajetória que merece ser comemorada. Além de ampliar e aprofundar nossos estudos, as conexões com esses pesquisadores e grupos de 


\section{pesquisa nacionais e internacionais geram uma sinergia que potencializa a construção}

de um lugar substancial para a arte na educação - em espaços formais e não formais.

\section{Analice Dutra Pillar}

Professora Titular da Faculdade de Educação da Universidade Federal do Rio Grande do Sul (FACED/UFRGS), Bolsista de Produtividade em Pesquisa do CNPq e Editora-Chefe da Revista GEARTE. Possui graduação em Artes Plásticas pela UFRGS, mestrado em Artes pela Escola de Comunicações e Artes da Universidade de São Paulo (ECA/USP) e doutorado em Artes pela ECA/USP. Realizou Estágio de Pós-Doutorado em Artes na Universidad Complutense de Madrid, Espanha. Atua como professora na graduação e no Programa de Pós-Graduação em Educação da FACED/UFRGS. Coordena o Grupo de Pesquisa em Educação e Arte (GEARTE/UFRGS/CNPq). É sócia da International Society for Education Through Art (InSEA), da Associação Brasileira de Estudos Semióticos (ABES) e da Associação Nacional de Pesquisadores em Artes Plásticas (ANPAP). Organizou e publicou artigos e livros na área do Ensino de Artes Visuais.

E-mail: analicedpillar@gmail.com

Currículo Lattes: http://lattes.cnpq.br/0033345213407184

\section{Maria Helena Wagner Rossi}

Graduada em Licenciatura em Desenho e Plástica. Mestre e Doutora em Educação na Universidade Federal do Rio Grande do Sul. Professora Titular da Universidade de Caxias do Sul (UCS) no Curso de Artes Visuais. Professora de Arte aposentada da rede estadual de ensino do Rio Grande do Sul. Líder do Grupo Interdisciplinar Arte, Cultura e Patrimônio - CNPq/UCS e vice-líder do Grupo de Pesquisa em Educação e Arte (GEARTE) - CNPq/PPGEDU/UFRGS. É coordenadora do Comitê de Ética em Pesquisa da Universidade de Caxias do Sul. É membro do Conselho de Representantes da FAEB. Foi vice-presidente da FAEB (Federação de Arte-Educadores do Brasil no biênio 2014-2016). É sócia da International Society for Education Through Art (InSEA). Tem publicado artigos em revistas e capítulos de livros sobre leitura de imagens e compreensão estético-visual. É autora do livro Imagens que falam: leitura da arte na escola, publicado pela Editora Mediação (5ª ed.: 2011; PNBE: 2011).

E-mail:mhwrossi@gmail.com

Currículo Lattes: http://lattes.cnpq.br/5017888754814808 